\title{
13 Patterns in Galápagos Magmatism Arising from
the Upper Mantle Dynamics of Plume-Ridge Interaction
}

\author{
Garrett Ito $^{1}$ and Todd Bianco ${ }^{2}$
}

\begin{abstract}
The origin of various patterns seen in Galápagos magmatism is investigated using numerical simulations of mantle plume-ridge interaction with the realistic geometry and evolution of the Galapágos Spreading Center (GSC). Models predict magma generation and composition from a mantle composed of fusible veins of material enriched in incompatible elements, and a more refractory depleted matrix. Model 1 simulates a low-viscosity plume, owing to a temperature-dependent mantle rheology; Model 2 includes the added dependence on water content, which leads to high viscosities in the dehydrated, shallow upper mantle. Model 1 produces the most favorable results. It shows how a modest crustal thickness anomaly observed along the Western GSC can arise from a plume with large excess temperatures (greater than $100^{\circ} \mathrm{C}$ ). Model 1 also predicts geographic patterns in magma isotopic compositions broadly resembling those observed along the GSC as well as around the Galapágos Archipelago. These patterns are predicted to arise out of the differences in melting depths between the enriched veins and depleted matrix, coupled with spatial variations in the rate of mantle upwelling and decompression melting. The results provide an alternative to traditional explanations involving the plume mixing with or entraining the ambient mantle. The models are still missing some essential factors, as indicated by the predicted increases, rather than the observed decrease in incompatible element concentration away from the hotspot along the GSC. Possible factors include a regional-scale zoning in incompatible element and water content within the plume, or melt migration that delivers a larger flux of incompatible-element-rich melts to the GSC.
\end{abstract}

\subsection{INTRODUCTION}

The Galapágos area was among the first of its kind to be recognized as an interaction of a mid-ocean ridge with a hotspot (Figure 13.1), originally inferred [Morgan, 1978; Schilling et al., 1982] and later shown to involve a mantle plume [Hooft et al., 2003; Villagomez et al., 2007]. A number of geophysical, petrologic, and geochemical studies of the area, especially over the past dozen years, have contributed to a basic characterization of the vari-

${ }^{1}$ Department of Geology and Geophysics, University of Hawai'i, Manoa

${ }^{2}$ Department of Geological Science, Brown University ability in mantle temperatures, compositions, melting conditions, and magmatic fluxes associated with plumeridge interaction [e.g., Harpp and White, 2001; Detrick et al., 2002; Harpp and Geist, 2002; Hooft et al., 2003; Schilling et al., 2003; Christie et al., 2005; Villagomez et al., 2007; Mittelstaedt et al., 2012]. However, what this variability indicates about the rheology of the upper mantle and the dynamical processes by which heat and mass transfer from the hotspot center toward and along the ridge axis are not well-understood. The relevant geodynamic modeling studies of plume-ridge interaction were done largely prior to the above studies and emphasized general fluid-mechanical aspects [Feighner et al., 1995; Ribe, 1996; Ito et al., 1997].

The Galápagos: A Natural Laboratory for the Earth Sciences, Geophysical Monograph 204. First Edition. Edited by Karen S. Harpp, Eric Mittelstaedt, Noémi d'Ozouville, and David W. Graham.

(C) 2014 American Geophysical Union. Published 2014 by John Wiley \& Sons, Inc. 
One enigma, for example, has arisen from geophysical evidence for a small crustal thickness anomaly $(2-3 \mathrm{~km})$, combined with evidence from lava petrology that, together, lead to estimates of small excess temperatures of only $20-30^{\circ} \mathrm{C}$ beneath the Western Galápagos Spreading Center (GSC) [Canales et al., 2002; Cushman et al., 2004]. These estimates are low compared to those of the excess temperature of the Galápagos plume itself $\left(30-150^{\circ} \mathrm{C}\right.$ [Villagomez et al., 2007] $130 \pm 60^{\circ} \mathrm{C}$ [Hooft et al., 2003]) or other mantle plumes $\left(100-200^{\circ} \mathrm{C}\right)$ [Wolfe et al., 1997; Allen et al., 1999; Wolfe et al., 2009; Putirka, 2012]. Thus one problem is to understand why the temperature anomaly apparently diminishes so quickly over the distance of only approximately $250 \mathrm{~km}$ between the hotspot center and the closest point of the Western GSC.

Another observation that has long confounded geodynamic modeling studies is that of the gradients in geochemistry along the GSC. Landmark studies led by Schilling in the 1980s [Schilling et al., 1982; Verma and Schilling, 1982; Schilling, 1985] revealed that lavas obtained from the GSC just north of the archipelago show similarities to Galápagos Archipelago lavas by having $\mathrm{Sr}, \mathrm{Nd}$, and $\mathrm{Pb}$ isotope signatures of material that, over geologic time, has been "enriched" in highly incompatible elements relative to less incompatible elements. With increasing distance east and west away from the hotspot center, the GSC lavas become more like "normal" (not influenced by hotspots) mid-ocean ridge basalts (MORBs) by having isotopic signatures of mantle that has remained more "depleted" in incompatible elements. These observations led to the notion that the Galápagos plume is feeding material to the ridge axis that is compositionally distinct from the ambient mantle, but explaining the gradual change in composition along the GSC remains problematic.
The original explanation for these compositional gradients was that as the plume material flows along the GSC, it becomes progressively diluted by the ambient mantle. This explanation is attractive in its simplicity, but geodynamic models of plume-ridge interaction predict little or no mixing or stirring between the plume and ambient mantle. The plume is predicted to spread along the axis and simply push the ambient material away so that only plume material is present in the melting zone over the whole distance of ridge influenced by the plume [Ito et al., 1997]. Recent evidence from $\mathrm{Pb}$ isotopes supports this conclusion [Ingle et al., 2010], showing that the ambient mantle is probably not being geochemically expressed along the plume-influenced portion of the Western GSC. Instead, the evidence shows that the mixing is between enriched plume material and depleted material that is distinct from that in the ambient mantle. Ingle et al. [2010] therefore produced a series of models that explained the along-axis gradients with a plume composed of two geochemical components that are being extracted at different rates along the GSC due to changes in the depth distribution of mantle flow and melting [Ito and Mahoney, 2005a]. Being only onedimensional (1D, varying with depth), these models did not address heat transfer from the hotspot toward and along the GSC, nor did they address the feasibility of the inferred depth variations in mantle flow in terms of the conservation laws that govern mantle convection in three dimensions (3D).

Yet another intriguing and poorly understood observation is the sideways " $U$ "-shaped geographic pattern in geochemical composition on and around the Galápagos Archipelago. This geochemical "horseshoe" (e.g., Figure 13.1B) indicates that the eruptions on the
(A)

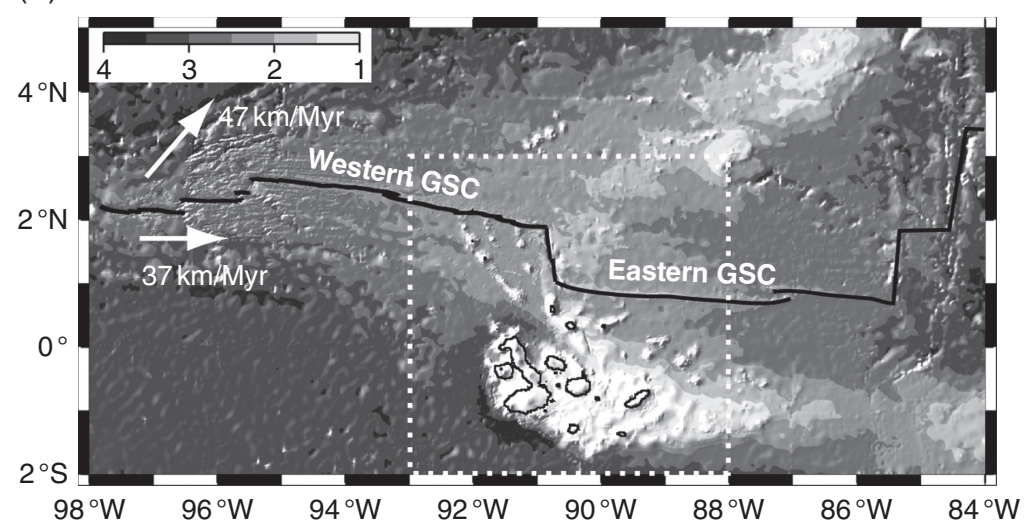

(B)

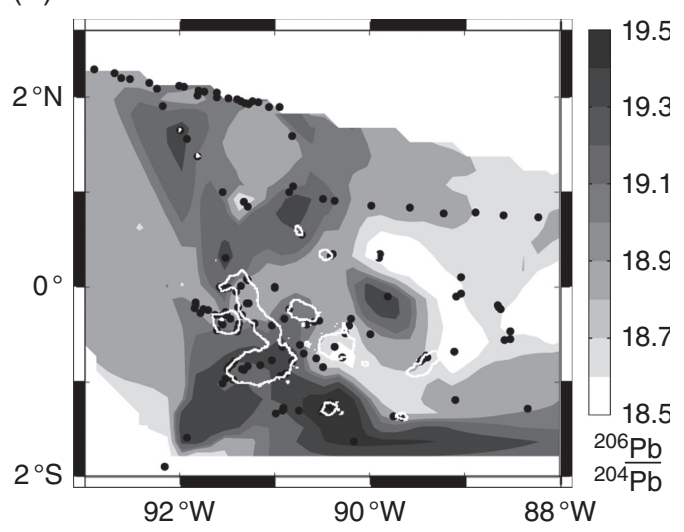

Figure 13.1 (A) Map of bathymetry (grayscale, in km, in upper left corner), the Galápagos Spreading Center (black lines) and the Galápagos Islands (outlined). Arrows show directions of absolute plate motion and are labeled with plate speed; dotted box outlines the area shown in (B). (B) ${ }^{206} \mathrm{~Pb} /{ }^{204} \mathrm{~Pb}$ from lava samples (black points from Ingle et al. [2010] and http://www.earthchem.org/) are averaged in $0.2^{\circ}$ grids and shaded around the Galápagos Archipelago. Islands are outlined in white. 
north, west, and south sides of the archipelago are preferentially sampling enriched mantle material, whereas lavas in the central and eastern part of the archipelago are preferentially sampling more depleted mantle [Geist, 1992; White et al., 1993; Harpp and White, 2001]. This pattern led to the idea that as the plume stem rises through the mantle, a small-scale circulation develops that entrains ambient depleted mantle into the center of the stem and transfers enriched material originally from the center to the outside of the stem in a torus pattern [Geist et al., 1988; Richards and Griffiths, 1989]. Another explanation is that the pattern reflects an asymmetric zoning in the composition of the plume stem, which was inherited from the deep source [Hoernle et al., 2000]. A similar interpretation has been made for other hotspots, such as Hawai'i [Abouchami et al., 2005], and used to infer a connection between compositions at the surface and heterogeneity in the deep mantle [Farnetani and Hofman, 2010; Weis et al., 2011].

The aim of this study is to link the above observations to the fluid-dynamics of plume-ridge interaction at the Galápagos system. The models simulate the realistic geometry and evolution of the GSC and motions of the Cocos and Nazca plates relative to the Galápagos hotspot. Two models are examined: Model 1 simulates a rheology that depends on temperature and pressure, but not composition, and Model 2 includes the compositional effects of water on mantle rheology. Beyond many prior geodynamic studies of the area, this study incorporates calculations of magma production and source heterogeneity to make quantitative predictions of magma flux, $\mathrm{Pb}$ isotope compositions, La/Sm trace-element ratios and $\mathrm{Na}$ compositions for comparison with observations. The results show that many (but not all) of the characteristic geographic patterns in Galápagos magmatism can arise solely out of the upper mantle dynamics of plume-ridge interaction.

\subsection{METHODS}

\subsubsection{Mantle convection}

The numerical computations simulate convection and melting of a mantle plume following Bianco et al. [2008, 2011] (Figure 13.2A). Finite elements are used to solve the equations describing conservation of mass, momentum, and energy of a viscous fluid with infinite Prandtl number and zero Reynolds number in Cartesian coordinates [Zhong et al., 2000]. The extended Boussinesq approximation applied, simulates the adiabatic temperature gradient, removal of latent heat due to melting but not viscous heating [Bianco et al. 2011]. In $x, y, z$, respectively, the box is $1,200 \times 1,900 \times 400 \mathrm{~km}$ on each side, discretized into $320 \times 192 \times 80$ finite elements, and has finest element sizes of $5 \times 5 \times 3.8 \mathrm{~km}$ (Figure 13.2A).
The model boundary conditions simulate a realistic GSC spreading rate $(28 \mathrm{~km} / \mathrm{Myr})$, absolute plate motion [Gripp and Gordon, 1990], and ridge geometry as it evolved in time since $6.3 \mathrm{Ma}$ [Wilson and Hey, 1995]. Potential temperature is $0^{\circ} \mathrm{C}$ at the surface and $1,300^{\circ} \mathrm{C}$ at the base, except in a circular patch where the plume is imposed. On this patch, the imposed excess temperature peaks in the center at $200^{\circ} \mathrm{C}$, decreases as a Gaussian function of radial distance, and is $1 / e$ times the peak at a radial distance of $65 \mathrm{~km}$. Over the $65-\mathrm{km}$ radius, the average excess temperature is approximately $130^{\circ} \mathrm{C}$, which is consistent with seismic constraints [Hooft et al. 2003; Villagomez et al. 2007]. The plume is centered at a location corresponding to just off the southeast shore of Fernandina at present day [Wilson and Hey, 1995]. Horizontal flow conditions on the top and bottom boundaries simulate the ridge geometry and absolute plate motions. Timeintegration spans $12 \mathrm{Myr}$ of total model time with the first 5.7 Myr needed to allow the plume to rise and spread beneath the lithosphere, and the final 6.3 Myr simulating the realistic evolution of the ridge and motion of the plates over the hotspot [Wilson and Hey, 1995]. The last time step represents the present-day configuration and activity from which the solutions of observables are produced.

Mantle viscosity $\eta$ depends on depth $z$, absolute temperature $T$, and water content $C_{w}$ relative to the starting content $C_{w 0}$ according to

$$
\eta=\eta_{0}\left(\frac{C_{s w}}{C_{w 0}}\right)^{r} \exp \left(\frac{E+\rho_{0} g z V}{R T}-\frac{E+\rho_{0} g D V}{R T_{0}}\right)
$$

where $\eta_{0}, T_{0}, \rho_{0}, g, D$ are the reference viscosity (used to define Rayleigh number), reference ambient mantle temperature at the base of the model $\left(1,573{ }^{\circ} \mathrm{C}\right.$; i.e., a potential temperature of $1,300^{\circ} \mathrm{C}$ ), reference mantle density $\left(3,300 \mathrm{~kg} / \mathrm{m}^{3}\right)$, acceleration of gravity $\left(9.8 \mathrm{~m} / \mathrm{s}^{2}\right)$, and maximum model depth $(400 \mathrm{~km})$, respectively. Activation energy $(E=250 \mathrm{~kJ} / \mathrm{mol})$ and activation volume $\left(V=6 \times 10^{-6} \mathrm{~m}^{3} / \mathrm{mol}\right)$ are reduced relative to laboratory-constrained values [Hirth and Kohlstaedt, 2003] for dislocation creep so that the above Newtonian rheological parameterization approximates the behavior of a power law (i.e., strain-rate-dependent) rheology [Christensen, 1984].

In Model 1, the exponent on water content is zero $(r=0$, in Equation 1) so viscosity varies only with pressure and temperature. The temperature effect is important in creating the thermal lithosphere, which generally thickens with distance from the ridge segments and evolves self-consistently with the solution of the energy equation due to changes in ridge segmentation and spreading rate. In 
(A)

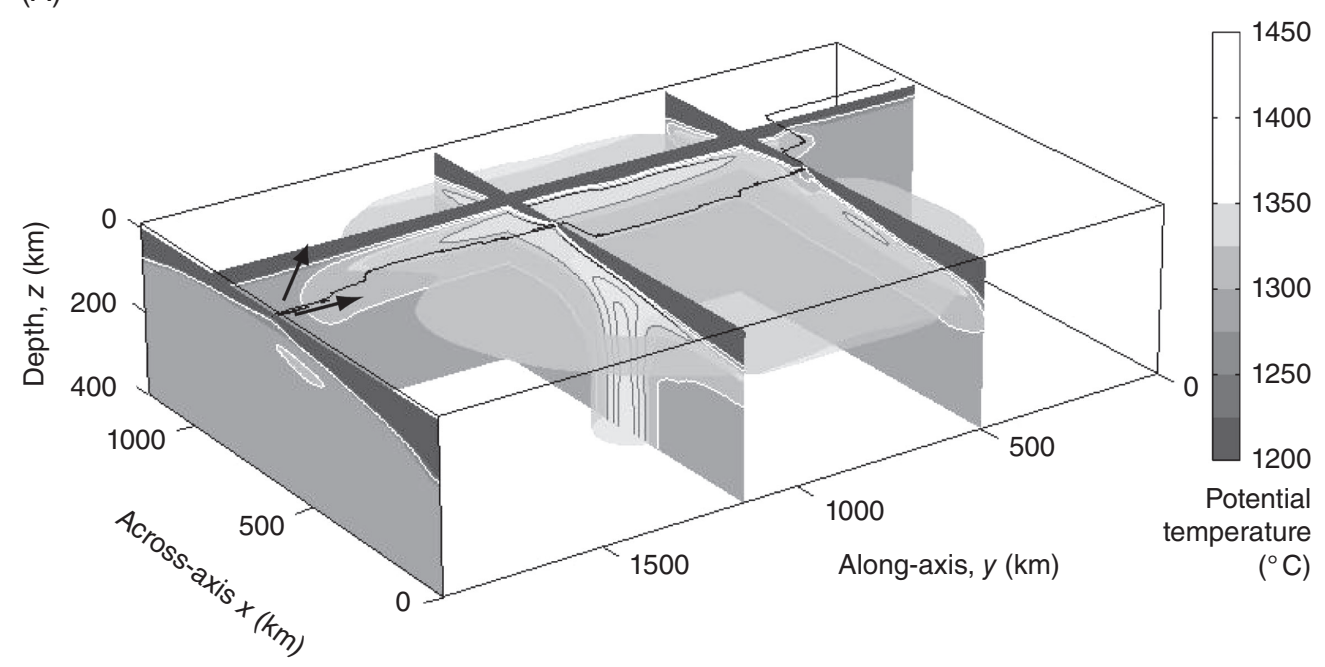

(B)

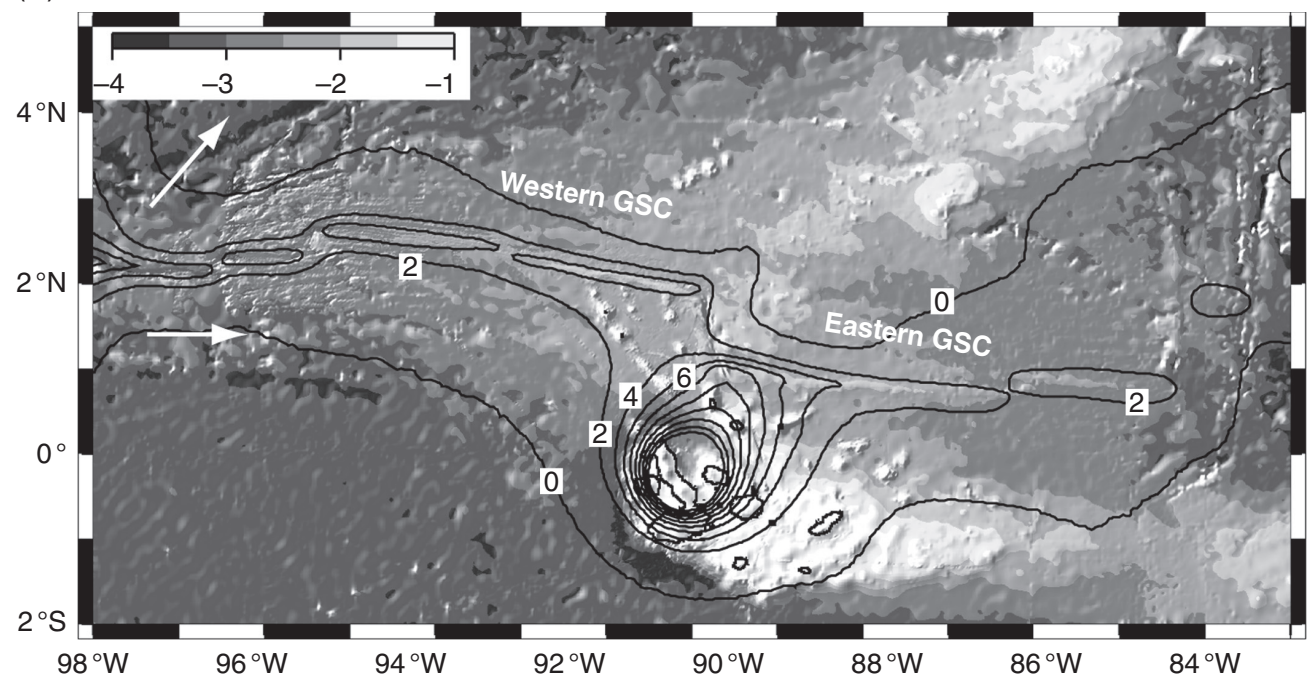

Figure 13.2 Model 1 (low-viscosity plume, without water-dependent rheology). (A) 3D perspective view of four vertical cross-sections of temperature (shaded) and the $1,330^{\circ} \mathrm{C}$ isosurface (translucent gray) in the numerical model. (B) Bathymetry map overlain with contours (every $2 \mathrm{~km} / \mathrm{Myr}$ ) of predicted depth-integrated melt flux. Arrows show directions of modeled absolute plate motions in both (A) and (B).

Model 2, $r=-1$, so viscosity also depends on water content [Hirth and Kohlstedt, 1996]. Water concentration in the solid residue $\left(C_{s w}\right)$ decreases from its starting concentration $\left(C_{w 0}\right)$ with melt depletion $F$ according to the fractional melting equation (with bulk partition coefficient of 0.01 [Cushman et al., 2004]). Thus, in Model 2, the dehydration of the mantle causes viscosity to increases from its value just below the melting zone to a maximum of 100 times (i.e., $\left.1 \leq\left(C_{s w} / C_{w 0}\right)^{r} \leq 100\right)$ after a couple of percent of melting [Hirth and Kohlstedt, 1996]. This creates a compositional lithosphere that encompasses most of partial melting zone in the sense that the buoyancy-driven flow of the plume is largely deflected beneath the dehydrated mantle layer, and within the layer, spatial variations in mantle flow and decompression melting are primarily driven passively by seafloor spreading [Ito et al., 1999; Bianco et al., 2013].

Rayleigh number (inversely proportional to reference viscosity, $\eta_{0}$ ) and plume thermal buoyancy flux are adjusted so that the ponding plume material spans approximately the same width (approximately 1,000 km) along the GSC at present day in both models. In Model 1, Rayleigh number and buoyancy flux are $9 \times 10^{5}$ and $3 \times 10^{3} \mathrm{~kg} / \mathrm{s}$, respectively; in Model 2, they are $1.4 \times 10^{6}$ and $5 \times 10^{3} \mathrm{~kg} / \mathrm{s}$. Buoyancy flux is measured at the base of the models. For comparison, buoyancy flux estimates of the Galápagos 
plume based on spreading rate and seafloor topography are $1-2 \times 10^{3} \mathrm{~kg} / \mathrm{s}$ [Sleep, 1990; Schilling, 1991].

\subsubsection{Model mantle heterogeneity, melting, and magma composition}

The melting and geochemistry calculations follow the main concepts of Ito and Mahoney [2005a] as implemented by Bianco et al. [2011, 2013]. We assume the mantle is composed everywhere of fusible veins or blobs [e.g., Sleep, 1984; Allégre and Turcotte, 1986] of material that is enriched in incompatible elements and radiogenic $\mathrm{Pb}$ (i.e., "enriched" material, EC), as well as a more refractory matrix that is depleted in incompatible elements and radiogenic $\mathrm{Pb}$ (i.e., depleted material, DC). The scale of the $\mathrm{EC}$ veins or blobs is assumed to be fine enough for the EC-DC mixture to be uniform at the scale of the control volume of the mantle continuum, but large enough so that the melting behavior of the two materials are chemically uncoupled. Chemical diffusion during melting, for example, would therefore have to be slow compared to the timescale of melt segregation by matrix compaction, and this condition is met for veins or blobs with minimum dimensions of decimeters to several meters (for $\mathrm{Os}, \mathrm{Sr}, \mathrm{Pb}$, Nd) [Kogiso et al., 2004].

The melting calculations are based on the parameterized solidus-pressure relations and rate change in extent of melting $F$ with temperature $T$ (above the solidus, $\partial F / \partial T)$ of Katz et al. [2003]. The more refractory DC matrix is treated as peridotite with $100 \mathrm{ppm}$ water (i.e., $C_{s w 0}=100 \mathrm{ppm}$ ) and the more fusible EC veins are treated as hydrous peridotite with $500 \mathrm{ppm}$ water (i.e., $\left.C_{s w 0}=500 \mathrm{ppm}\right)$. The bulk water content is thus $140 \mathrm{ppm}$, which is intermediate between estimated contents of the source of normal mid-ocean ridge basalt (NMORB) and the mantle component FOZO [Hirth and Kohlstedt, 1996; Workman et al., 2006]. One effect of water is on viscosity in Model 2. In this model, the viscosity of the bulk mantle mixture is computed as the harmonic mean of the viscosities of the DC and EC materials (see Bianco et al. [2013] for details) weighted by their respective fractions of the mantle mixture. Another important effect of water is its influence on the depth of melting. In both Model 1 and Model 2, EC begins melting at a greater depth than DC; therefore, the rate that incompatible elements are being extracted from each material by melting can vary geographically when the rate of mantle upwelling varies with depth and geographic position.

The concentration of an incompatible trace element in the melt produced from EC and DC are governed by modal, fractional melting using partition coefficients of Salters and Stracke [2004] and modal proportions of Ito and Mahoney [2005a], which vary with extent of melting,

$$
\begin{aligned}
E^{i}= & \frac{C^{i}}{C_{0}^{i}}=\frac{1}{D_{0}}\left(1-F^{i}\right)^{\left(\frac{1}{D_{0}}-1\right)}, 0<F^{i} \leq F_{1} \\
= & \frac{1}{D_{1}}\left(1-F_{1}\right)^{\left(\frac{1}{D_{0}}-\frac{1}{D_{1}}\right)}\left(1-F^{i}\right)^{\left(\frac{1}{D_{1}}-1\right)}, F_{1}<F^{i} \leq F_{2} \\
= & \frac{1}{D_{2}}\left(1-F_{1}\right)^{\left(\frac{1}{D_{0}}-\frac{1}{D_{1}}\right)}\left(1-F_{2}\right)^{\left(\frac{1}{D_{1}}-\frac{1}{D_{2}}\right)}\left(1-F^{i}\right)^{\left(\frac{1}{D_{2}}-1\right),} \\
& F_{2}<F^{i} .
\end{aligned}
$$

Here, $i$ is the index for each material type (i.e., $i=1$ for DC and $i=2$ for EC), $F^{i}$ is the extent of melt depletion of material $i$, and $E^{i}$ is the factor by which the concentration of material $i$ in the melt $C^{i}$ is enriched, relative to that of the starting solid $C_{0}^{i}$. The first interval $\left(0<F^{i} \leq F_{1}\right)$ is in the garnet stability field, the second is in the spinel field $\left(F_{1}<F^{i} \leq F_{2}\right)$, and the last $\left(F_{2}<F^{i}\right)$ is after clinopyroxene has melted out. The bulk partition coefficients for the three intervals are $D_{0}, D_{1}$, and $D_{2}$, respectively. For simplicity, we assume the garnet stability field ends and the spinel field begins abruptly at a pressure of $30 \mathrm{GPa}$; therefore, the extent of depletion $\left(F_{I}\right)$ at which this transition occurs depends on temperature. The extent of depletion at which clinopyroxene is exhausted $F_{2}$ is assumed to be pressuredependent [Katz et al. 2003], and therefore the point of clinopyroxene-out depends on temperature and depth.

To predict the incompatible element composition of an erupted magma, we assume an idealized situation of perfect mixing of melts accumulated from a given volume of mantle $V_{m}$,

$$
\bar{C}=\frac{\sum_{i=1}^{2} \phi^{i} C_{0}^{i} \int_{V_{m}} E^{i}\left(\partial F^{i} / \partial t\right) d V_{m}}{\sum_{i=1}^{2} \phi^{i} \int_{V_{m}}\left(\partial F^{i} / \partial t\right) d V_{m}} .
$$

Here $\bar{C}$ is the accumulated (average) melt composition, $\phi^{i}$ is the fraction of each material present in the mantle ( $\phi^{l}$ for DC and $\phi^{2}$ for EC), and $V_{m}$ is the volume in the mantle melting zone from which the melts have accumulated. Correspondingly, the equation describing the $\mathrm{Pb}$ isotope composition of accumulated melts is

$$
\left(\frac{\overline{\mathrm{Pb}}}{{ }^{204} \mathrm{~Pb}}\right)=\frac{\sum_{i=1}^{2}\left(\frac{{ }^{206} \mathrm{~Pb}}{{ }^{204} \mathrm{~Pb}}\right)^{i} \phi^{i} C_{0 P b}^{i} \int_{V_{m}} E_{P b}^{i}\left(\partial F^{i} / \partial t\right) d V_{m}}{\sum_{i=1}^{2} \phi^{i} C_{0 P b}^{i} \int_{V_{m}} E_{P b}^{i}\left(\partial F^{i} / \partial t\right) d V_{m}}
$$

where material $i$ has an isotope composition of $\left({ }^{206} \mathrm{~Pb} /{ }^{204} \mathrm{~Pb}\right)^{i}$, an initial $\mathrm{Pb}$ concentration of $C_{0 P b}^{i}$, and 
produces melt at a rate $\partial F^{i} / \partial t$, with incompatible element concentrations elevated relative to the source $\left(C_{0 P b}^{i}\right)$ by $E_{P b}^{i}$ (due to fractional melting). Equations 13.3 and 13.4 show that the accumulated melt compositions are proportional to the rate that the incompatible elements are liberated from the solid by decompression melting. This assumption is appropriate for the situation of negligible melt-solid interaction during melt migration, as is consistent with the fractional melting approximation [Johnson et al., 1990], or appropriate in the presence of melt-solid reaction, so long as such reactions preserve the above proportionality with decompression melting rate. This assumption is discussed later in this manuscript.

The models do not explicitly simulate melt migration, and therefore simplifying assumptions are used to determine which volume $V_{m}$ of mantle feeds magma to the ridge axis versus to off-axis hotspot volcanoes. Namely, we take the distance in $x$ (perpendicular to the ridge) between each mantle melting point and the ridge axis, $\Delta x$, and the horizontal distance between the melting point and the center of the hotspot, $\Delta r$ (Figure 13.3A). The hotspot center is defined as the geographic location within $100 \mathrm{~km}$ of the center of the plume stem where the depth-integrated magma production rate is greatest. If $\Delta x / \Delta r<$ a cut-off value of $\xi$, then that parcel of melt is assumed to migrate perpendicularly to and erupt at the GSC (as would occur if melt migrates along the ridge-ward sloping base of the lithosphere [e.g., Sparks and Parmentier, 1991]); if $\Delta x / \Delta r$ is greater than the cut-off, the melt is assumed to erupt at an off-axis volcano. The important free parameter is the ridge-to-hotspot distance cut-off ratio $\xi$. Results show that for the values considered $(\xi=0.5-1.0)$, predictions of crustal thickness are sensitive to $\xi$, predictions of incompatible element ratios are moderately sensitive to $\xi$, and predictions of isotope compositions are insensitive to $\xi$.

Equations 13.2-13.4 are used to predict ${ }^{206} \mathrm{~Pb} /{ }^{204} \mathrm{~Pb}$ as an example isotope ratio, $\mathrm{La} / \mathrm{Sm}_{\mathrm{PM}}$, as an example ratio of highly-to-moderately incompatible elements (subscripts denoting the ratio relative to that of McDonough and Sun's [1995] primitive mantle), and $\mathrm{Na}$ as an example of a moderately incompatible major element. DC is assumed to have the $\mathrm{Pb}, \mathrm{La}$, and $\mathrm{Sm}$ concentrations (i.e., $C_{0}^{1}$ for each species) of the average depleted mantle "DMM" of Workman and Hart [2005] and the ${ }^{206} \mathrm{~Pb} /{ }^{204} \mathrm{~Pb}$ ratio (17.5) of the "DM" component of Schilling et al. [2003]. The $\mathrm{Na}_{2} \mathrm{O}$ content of DC $(0.26 \mathrm{wt} \%)$ is twice that of Workman and Hart's [2005] DMM and is intermediate between Cushman et al.'s [2004] "E-MORB" and "T-MORB" source compositions for the Western GSC. EC is assumed to have nine times more $\mathrm{Pb}$, three times more $\mathrm{La}$, and an equivalent amount of Sm and Na2O relative to McDonough and Sun's [1995] primitive mantle. EC's ${ }^{206} \mathrm{~Pb} /{ }^{204} \mathrm{~Pb}$ ratio of 20.3 is similar to the "FOZO" component of Stracke et al. [2005] (i.e., 20.0). The veins of EC are assumed to make up $\left(\phi^{2}=\right) 10 \%$ of the mantle and the DC matrix makes up the remaining $\left(\phi^{l}=\right)$
$90 \%$. The source compositional parameters of EC ( $\phi^{2}$ and $C_{0}^{2}$ 's) were chosen somewhat arbitrarily. The chosen values define a reference source composition and serve to illustrate the general behavior of the processes simulated. The values also yield model compositions along the GSC, similar to those observed.

The source composition in the model is greatly simplified compared to that inferred from recent geochemical studies of the Galápagos area. These studies show that, in addition to one or more depleted components [Ingle et al., 2010], there are multiple non-depleted components in the Galápagos upper mantle [Geist et al., 1988; White et al., 1993; Harpp and White, 2001]. We do not aim to address the origin of the complete diversity of magma heterogeneity in the Galápagos area, but only to examine how variable upper mantle flow and melting influence the geochemical expressions of refractory versus more fusible material in erupted magma, as it is the differences in melting depth to which our calculations are sensitive. Hence, we assume that the depleted isotopic components in the Galápagos area are refractory and associate their basic geochemical characteristics with the model DC material, and assume the other components are more fusible and associate their non-depleted or enriched characteristics with EC.

\subsection{RESULTS: PREDICTED AND OBSERVED MAGMA FLUX}

\subsubsection{Model 1: Plume with low viscosity, without a dependence on water content}

In Model 1, the viscosity of the plume is low, due to its high temperature. One outcome is a relatively thin layer of ponding plume material, which is contained between a depth of approximately $100 \mathrm{~km}$ (Figures 13.2A, 13.3B, and 13.3i) and the base of the thermal lithosphere. The variation in lithospheric thickness over the distance between the plume stem and ridge is comparable to the thickness of the ponding plume layer, and hence the sloping base of the lithosphere tends to draw plume material toward and along the ridge axis.

The other outcome of the low viscosities is that the melt production rate changes rapidly with distance around the plume stem; this is visualized by the depth-integrated melt production rate, projected onto the surface (Figures 13.2B, 13.3A). The highest rates of melt production (e.g., greater than $4 \mathrm{~km} / \mathrm{Myr}$ ) are near the ridge axis and in an oval-shaped area extending from the southern tip of Isabela to the western end of the Eastern GSC (the segment just east of the transform fault near 91 degrees W; Figures 13.2A, 13.3A). This area is above the plume stem where the mantle is hottest and upwelling most rapidly (Figure 13.3I). The N-NE elongation of this zone is heavily influenced by lithosphere structure. The lithosphere is thinner N-NE of the hotspot because of the closer proximity to the Eastern GSC, and this 
(A)
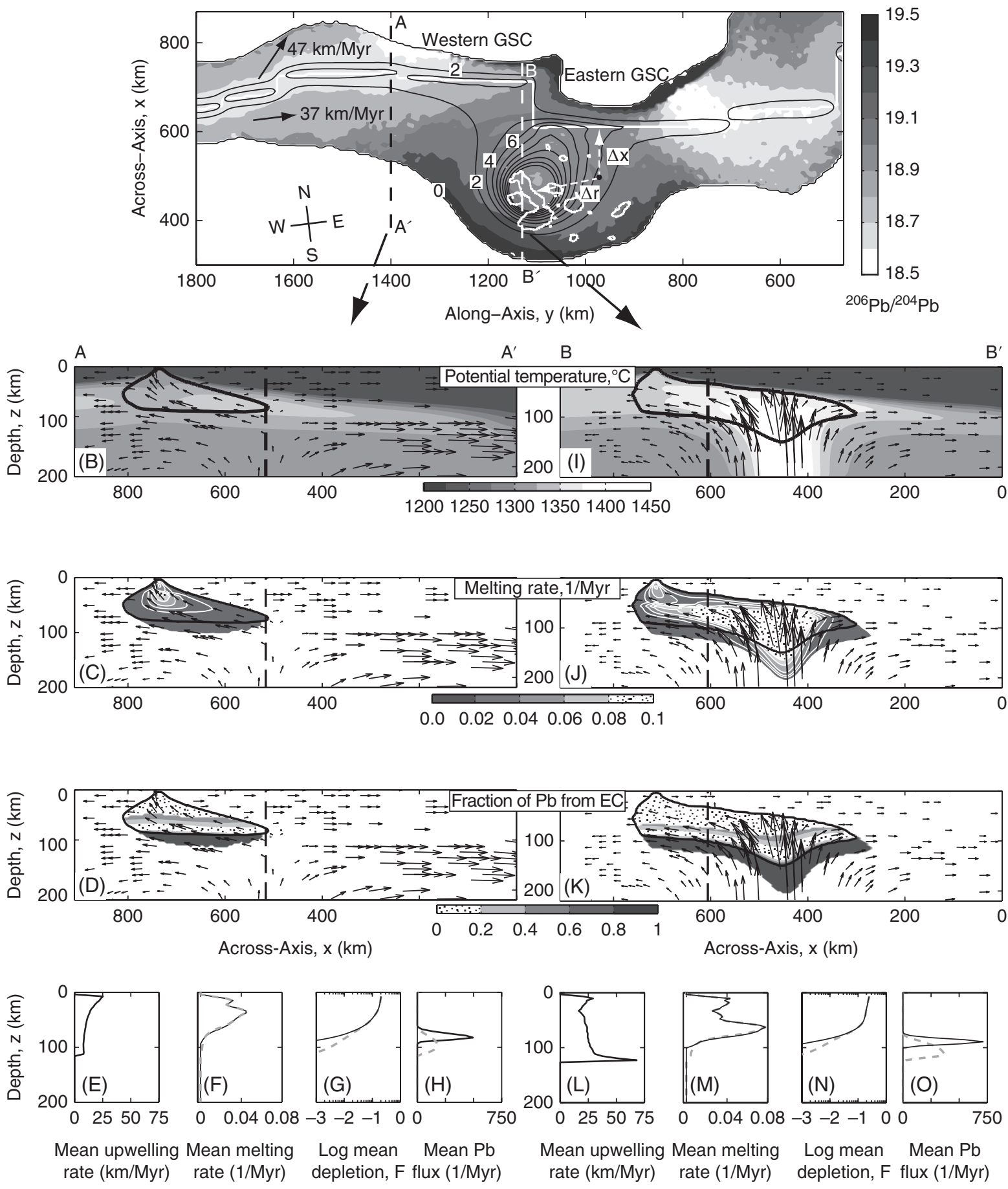

$$
\begin{aligned}
& \text { Mean upwelling Mean melting Log mean Mean } \mathrm{Pb} \\
& \text { rate }(\mathrm{km} / \mathrm{Myr}) \text { rate }(1 / \mathrm{Myr}) \text { depletion, } \mathrm{F} \text { flux }(1 / \mathrm{Myr})
\end{aligned}
$$

Figure 13.3 Model 1 (low-viscosity plume, without water-dependent rheology). Map of melt flux (contours every $2 \mathrm{~km} / \mathrm{Myr}$ ) and depth-averaged ${ }^{206} \mathrm{~Pb} /{ }^{204} \mathrm{~Pb}$ (gray). Plate motion is shown with small black arrows; ridge segments and segment offsets are marked by solid white lines. If $\Delta x / \Delta r<\xi$ (distances marked by dashed arrows), then melt from the black dot is assumed to accrete at the ridge axis at the tip of the north-pointing dashed arrow. Dashed lines mark locations of vertical cross-sections located at $y=1,400 \mathrm{~km}\left(A-A^{\prime}\right.$, panels $\left.B-H\right)$, and $y=1,130 \mathrm{~km}\left(B-B^{\prime}\right.$, panels I-O). (B and I) Vertical cross-sections of potential temperatures (gray scale in ${ }^{\circ} \mathrm{C}$ ) and the area of DC melting (black contour). Small arrows show mantle flow in the plane of the cross section: in $\mathrm{A}-\mathrm{A}^{\prime}$ the flow is primarily in the plane, but for $B-B^{\prime}$, the largest component of flow is out of the plane (velocity in $y$ direction away from the plume is rapid, but not shown). Dashed line separates melt that is assumed to accrete at the ridge axis versus the off-axis volcanoes. (C and J) Melting rate (grayscale in $\mathrm{Myr}^{-1}$, contours every $0.02 \mathrm{Myr}^{-1}$ ) of EC; other parts the same as ( $\mathrm{B}$ and $\mathrm{I})$. ( $\mathrm{D}$ and $\mathrm{K}$ ) Fraction of $\mathrm{Pb}$ that is being transferred to the melt from $\mathrm{EC}: 0$ means all $\mathrm{Pb}$ is from DC, 1 means all $\mathrm{Pb}$ is from EC; other parts the same as ( $\mathrm{B}$ and $\mathrm{I}$ ). ( $\mathrm{E}-\mathrm{H}$ and $\mathrm{L}-\mathrm{O}$ ) Bottom row shows properties (as labeled) averaged horizontally across the zone of melting that contributes to the ridge axis (i.e., shown in the panels above), weighted by melting rate $\partial F^{\prime} \partial t$ at each point, and varying as a function of depth for each mantle material (solid for DC, dashed for EC). "Mean Pb flux" is the mean rate of Pb being transferred from solid to melt in concentration (normalized by source concentration) per Myr. 
(A)

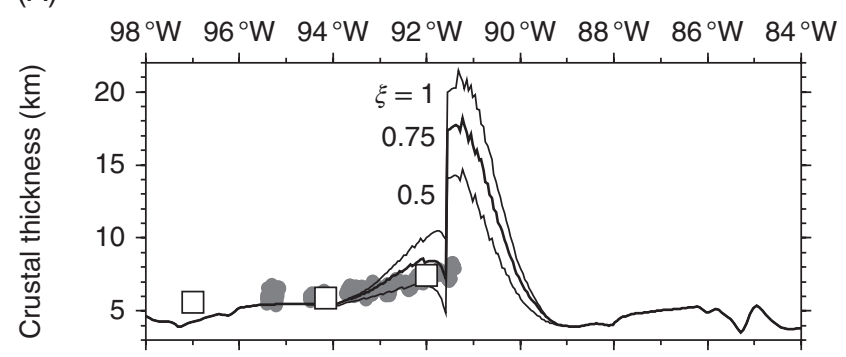

(B)

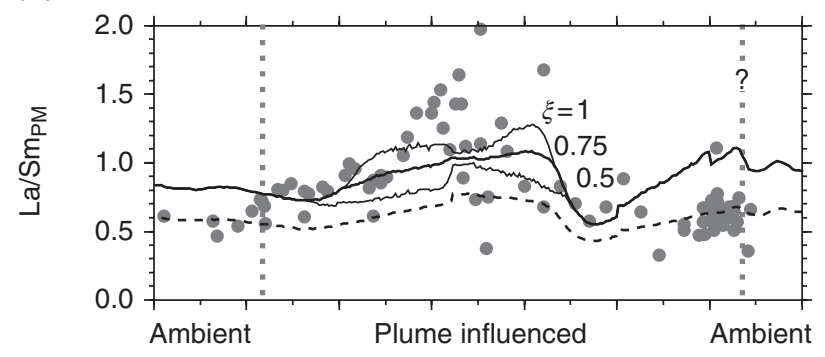

(C)

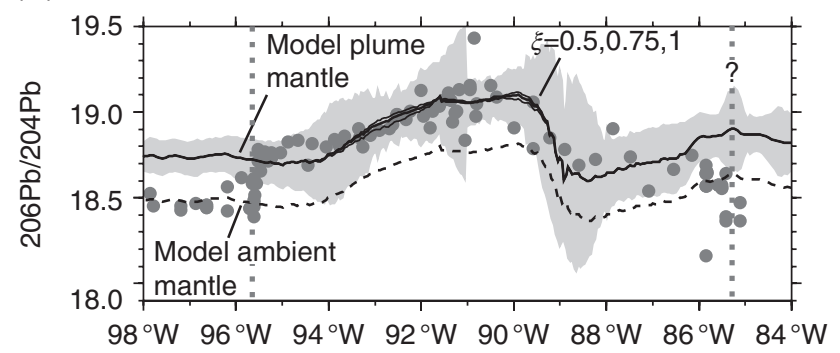

Figure 13.4 Model 1 (low-viscosity plume, without waterdependent rheology) predictions (solid curves) are compared to observations (gray dots) along the GSC. Three solid curves are for shown values of $\xi$ (see text), and the model plume source compositions; dashed curves are for $\xi=0.75$ and a more depleted, ambient mantle composition. Dotted vertical line near 95.5 degrees $\mathrm{W}$ marks the probable compositional boundary between plume mantle and ambient mantle; the location of the boundary near 85.3 degrees $\mathrm{W}$ is uncertain, as indicated by "?". (A) Predicted and seismically measured crustal thicknesses (gray from multi-channel reflection, white squares from seismic refraction [Canales et al., 2002]) along the GSC. (B) and (C) Geochemical data from Ingle et al. [2010] and http://www.earthchem.org/.

allows for more total decompression melting. The lithosphere also thins more rapidly to the N-NE, and this allows for more rapid upslope flow and melting along its base.

The localized area of high magma production predicted by Model 1 implies that magma need not migrate laterally very far to feed the active Galápagos Islands as well as the numerous volcanoes and volcanic lineaments between the main islands and the GSC [e.g., Harpp and Geist, 2002; Sinton et al., 2003; Mittelstaedt et al., 2012]. The total vol- ume flux of magma that is assumed to erupt off of the GSC and presumably as off-axis volcanism is $4.5-5.3 \times 10^{5} \mathrm{~km}^{3} /$ Myr, for $\xi=0.5-1.0$, respectively. These flux predictions are of the same order as those needed to build archipelago topography (1-3 $\times 10^{5} \mathrm{~km}^{3} / \mathrm{Myr}$ [Ito et al., 1997]).

Along the ridge axis, the predicted magma production rate is represented as crustal thickness so that it can be easily compared to observations (Figure 13.4A). Crustal thickness is predicted to be largest on the Eastern GSC, being $14-21 \mathrm{~km}$, for $\xi=0.5-1.0$, respectively. These large thicknesses are primarily caused by the rapid upwelling and decompression melting between the hotspot center and this section of the GSC. Gravity studies suggest that the crust along this section of the GSC is much thinner than predicted by this particular model [Ito and Lin, 1995; Mittelstaedt et al., Chapter 14, this volume]; however, a more definitive test of the current prediction could be performed with a seismic refraction study. In contrast, on the Western GSC (west of 90.8 degrees W), the maximum crustal thicknesses are predicted to be significantly lower at $7-10.5 \mathrm{~km}$, for $\xi=0.5-1.0$, respectively (Figure 13.4A). Crustal thickness measurements from a seismic refractions study are available along the Western GSC, and the model predictions are consistent with these measurements. The relatively small excess crustal thicknesses predicted along the Western GSC result from the low plume viscosities, which cause a large portion of the plume to rise above the solidus and melt near the hotspot center and then flow northward toward the Western GSC as a relatively thin and partially depleted plume layer (Figure 13.3I). Thus, even though this material started off with a peak excess temperature of $200^{\circ} \mathrm{C}$ (and an average of $130^{\circ} \mathrm{C}$ ), by the time it gets to the melting zone of the Western GSC, it can only generate as much melt as mantle having a much smaller excess temperature of less than $50^{\circ} \mathrm{C}$. The above predictions, however, yield problems with incompatible element concentrations in the GSC lavas, which are discussed below.

\subsubsection{Model 2: High viscosity in the shallowest upper mantle with the dependence on water content}

In Model 2, the simulated extraction of water due to partial melting creates a strong, dehydrated layer in the shallowest upper mantle that acts like a compositional lithosphere. This layer is thickest (approximately $140 \mathrm{~km}$ ) over the hot plume stem and thins away from this location to a thickness of approximately $80 \mathrm{~km}$ just beyond the outer edges of the ponding plume material. The layer of ponded plume material extends from the base of the thermal lithosphere to a depth more than $150 \mathrm{~km}$ (Figures 13.5A, 13.6B, and 13.6I), and is thus about 50\% thicker than that in Model 1.

This viscosity structure dramatically changes the pattern of magma production compared to that of Model 1. 

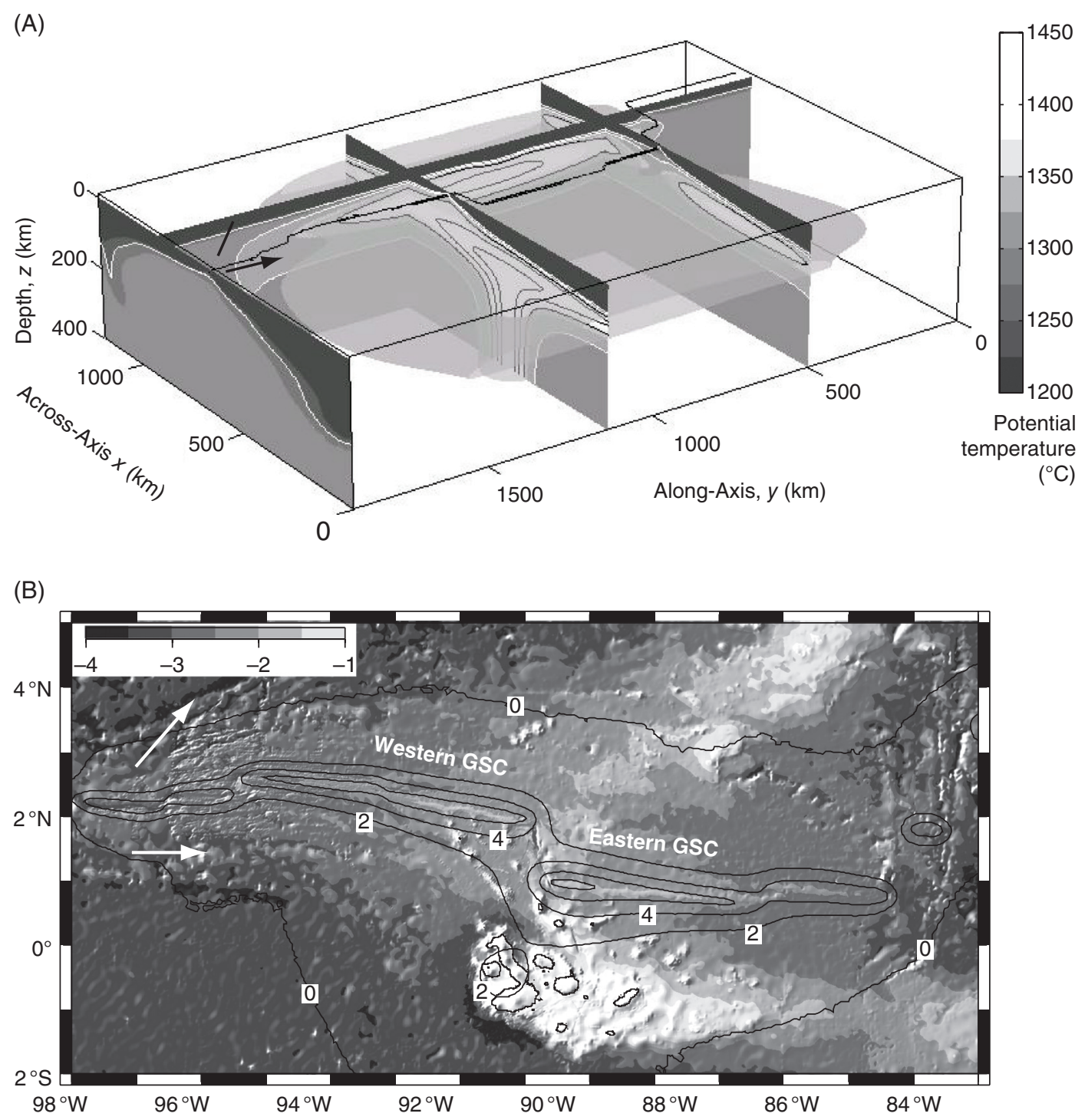

Figure 13.5 Same as Figure 13.2, but for Model 2 (high-viscosities in the shallowest upper mantle plume due to water-dependent rheology).

Because most of the melting zone in Model 2 is dehydrated, stiff, and flowing as a passive response to seafloor spreading, the depth-integrated magma production rate is highest beneath the GSC, and has only a smallamplitude, local peak over the plume stem (Figures $13.5 \mathrm{~A}, 13.6 \mathrm{~A})$. The total flux of magma that is predicted to feed off-axis volcanism is $1.1-1.6 \times 10^{5} \mathrm{~km}^{3} / \mathrm{Myr}$. These values are again of the same order as those estimated based on observed topography $\left(1-3 \times 10^{5} \mathrm{~km}^{3} / \mathrm{Myr}\right.$ [Ito et al., 1997]); however, magma production is not predicted to be as localized around the archipelago as it is in Model 1, but to occur over a much broader area. Model 2 would therefore require magma to migrate hundreds of kilometers laterally to feed the islands and smaller volcanoes between the main islands and the GSC.
The predicted crustal thickness again peaks on the western end of the Eastern GSC, but in contrast to the results of Model 1, the crustal thickness of Model 2 decreases gradually and nearly symmetrically east and west of this peak (Figure 13.7A). The dehydrated layer minimizes the amount of melting that occurs near the hotspot center, and therefore the layer of plume material feeding the melting zone of the Western GSC is thick, largely pristine (Figures 13.6A,I), and is able to produce about as much melt as it would with the full excess temperature of $200^{\circ} \mathrm{C}$. The resulting crustal thicknesses are much larger than those determined seismically along the Western GSC. If Model 2 is to represent the natural system, much less melt would have to be migrating to the GSC than predicted, while more melt would have to feed the off-axis volcanoes. 


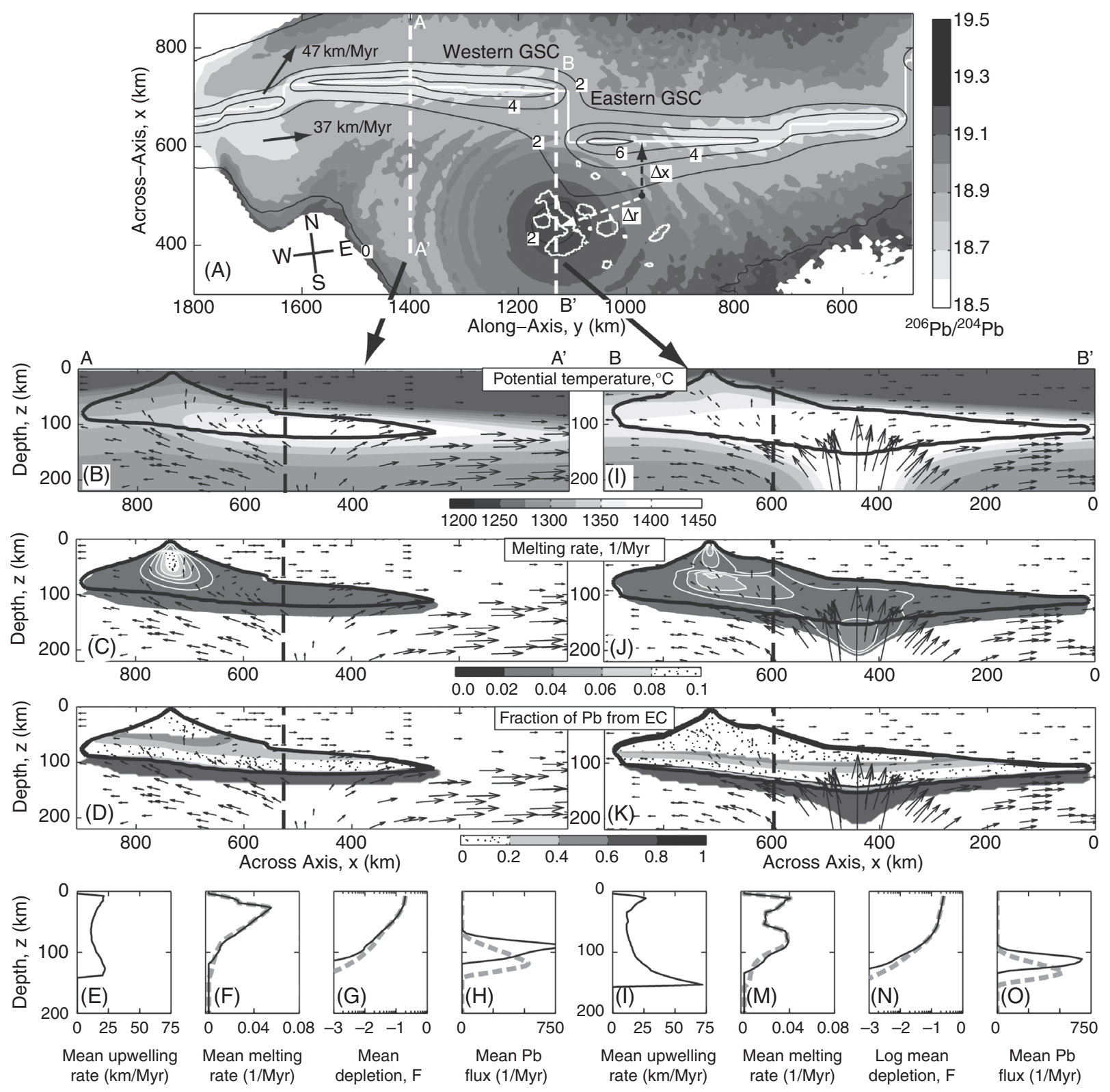

Figure 13.6 Same as Figure 13.4 but for Model 2 (high-viscosities in the shallowest upper mantle plume due to water-dependent rheology). The circular undulations in (A) are artifacts of small errors in the melting calculations that become amplified by the highly non-linear dependence of Pb flux on extent of partial melting $F$. (B-K) Again, the small arrows in the cross-sections show the components of mantle flow in the two planes, whereas the largest component is out of the plane in B-B'.

\subsection{RESULTS: PREDICTED AND OBSERVED MAGMA COMPOSITIONS}

\subsubsection{Model 1 geochemical variations}

The relative contributions of EC (again representing non-depleted or enriched materials in the Galápagos mantle) versus DC (representing depleted material[s]) to the magma in Model 1 are reflected by a map of ${ }^{206} \mathrm{~Pb} / 204 \mathrm{~Pb}$ (Figure 13.3A). These compositions are depth averages, weighted by the rate that $\mathrm{Pb}$ is transferred from each component to the melt (Equation 13.4 with $V_{m}$ being a vertical column extending through the melting zone). Near the hotspot, the contribution from EC (high ${ }^{206} \mathrm{~Pb} /{ }^{204} \mathrm{~Pb}$ ) is predicted to be maximal in a broad arc wrapping around the far southern border of the melting zone, moderately 
(A)

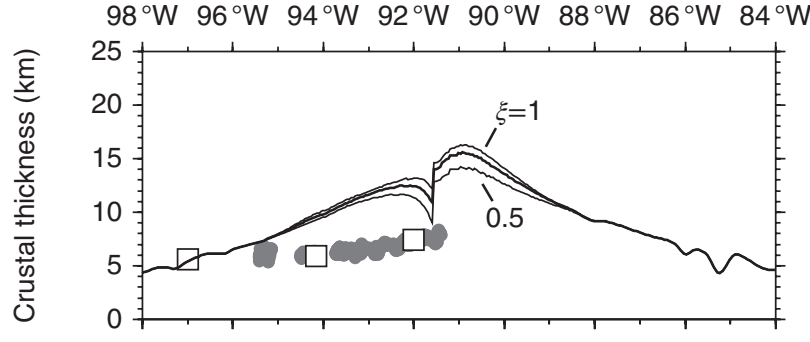

(B)

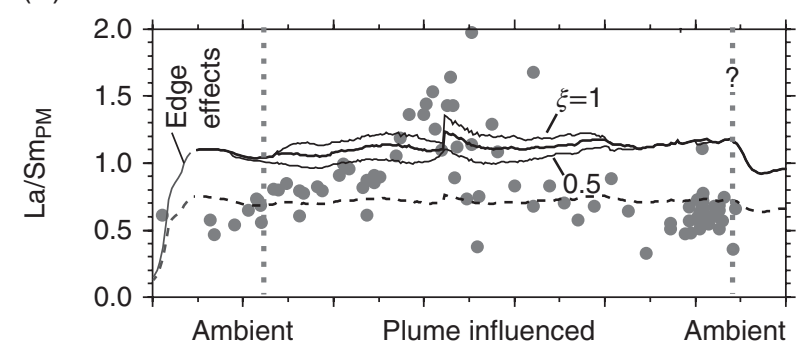

(C)

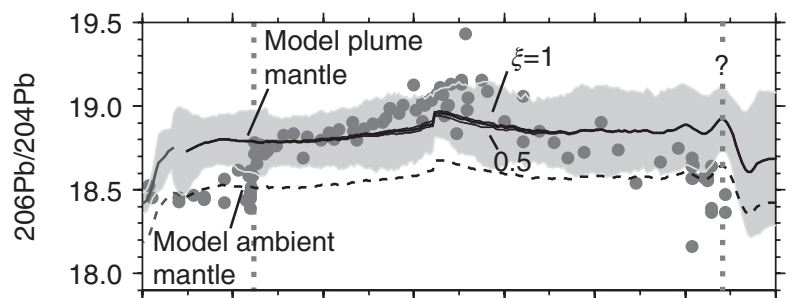

$98^{\circ} \mathrm{W} 96^{\circ} \mathrm{W} 94^{\circ} \mathrm{W} 92^{\circ} \mathrm{W} 90^{\circ} \mathrm{W} 88^{\circ} \mathrm{W} 86^{\circ} \mathrm{W} 84^{\circ} \mathrm{W}$

Figure 13.7 Same as Figure 13.6 but for Model 2 (high-viscosities in the shallowest upper mantle plume due to waterdependent rheology). Effects of the free boundary on the far left $(y=1900 \mathrm{~km})$ side of the model produce spurious results for magma composition west of approximately $96.5^{\circ} \mathrm{W}$.

prevalent to the northwest and southeast around the hotspot center, and least prevalent between the hotspot center and the ridge axis. These predictions arise out of the dynamics of mantle flow and melting: the southern edges of the hotspot melting zone are more influenced by EC, where this material is the primary material melting, and the central, north, and northeast side of the hotspot see a relatively greater contribution from DC, where DC and EC are melting at more similar rates (Figures 13.3J-K). An analogous process for creating more depleted compositions between the hotspot center and the ridge axis has been proposed in recent geochemical studies [Hoernle et al., 2000; Gibson and Geist, 2010]. The predicted arc of high ${ }^{206} \mathrm{~Pb} /{ }^{204} \mathrm{~Pb}$ around the perimeter of the hotspot melting zone crudely resembles the horseshoe shape of the observed isotope pattern around the Galápagos Archipelago (Figure 13.1B). The predicted pattern, however, spans across the whole melting zone and is thus wider than the observed pattern, which is restricted more closely to the volcanoes on and near the archipelago. Thus, Model 1 could explain the gross horseshoe shape of the observed pattern if melt migrates from where it is produced in the mantle inward toward the archipelago over modest lateral distances (less than $100 \mathrm{~km}$ ).

Model 1 also predicts appreciable gradients in geochemistry along the GSC (Figure 13.4B, C). The model compositions are based on the incompatible-element fluxes from EC and DC, averaged over all points in the mantle feeding melt to the ridge axis $\left(V_{m}\right.$ in Equation 4 is a cross-section perpendicular to the ridge axis, bounded in $x$ by the criteria $\Delta x / \Delta r<\xi$ ). Along the GSC, models predict $\mathrm{La} / \mathrm{Sm}_{\mathrm{PM}}$ and ${ }^{206} \mathrm{~Pb} /{ }^{204} \mathrm{~Pb}$ to be higher and, thus, more similar to the ratios of EC just north of the hotspot, and to become lower and more like those of DC with increasing distance away from the hotspot. This prediction arises because near the plume stem, buoyant upwelling enhances decompression melting in the deepest part of the melting zone where $\mathrm{EC}$ is losing incompatible elements, relative to the shallower part, where DC is losing incompatible elements (Figures 13.3J-N). This creates a comparatively large flux of incompatible elements from EC (Figure 13.3O). Farther away from the plume stem, mantle upwelling and melting rates are both lower where EC is losing its incompatible elements, and therefore the average incompatible-element flux from EC relative to DC is lower (Figures 14.3C-H). The predicted values and variations in compositions are comparable to those observed over the length of ridge axis that is influence by the Galápagos hotspot $\left(95.5^{\circ} \mathrm{W}\right.$ to approximately $\left.85.3^{\circ} \mathrm{W}\right)$.

\subsubsection{Model 2 geochemical variations}

Figure 13.6A shows a map of depth-averaged ${ }^{206} \mathrm{~Pb} /{ }^{204} \mathrm{~Pb}$ composition for Model 2. The pattern is very different from that of Model 1 in that the highest contributions from $\mathrm{EC}$ (again, high ${ }^{206} \mathrm{~Pb} /{ }^{204} \mathrm{~Pb}$ ) no longer wrap around the hotspot center, but instead occur directly over it. This pattern is again the result of the stiff dehydrated layer. Because the bottom boundary of this layer is near the base of the DC melting zone, thermal buoyancy significantly enhances mantle upwelling and thus the flux of $\mathrm{Pb}$ for $\mathrm{EC}$, but not for DC. The enhanced upwelling, melting, and $\mathrm{Pb}$ flux from EC is largest over the hot plume stem and decreases away from it. The predicted pattern in ${ }^{206} \mathrm{~Pb} / 204 \mathrm{~Pb}$ is unlike the pattern observed around the Galápagos Archipelago.

Along the GSC, the predicted geochemical compositions show little variation but instead maintain nearly uniform values at the longest wavelength. This is the result of the stiff dehydrated layer minimizing the along-axis variations in the buoyancy-driven mantle flow (Figures 13.6B$\mathrm{O})$. Here, buoyancy-driven flow is again restricted to the 
base of the EC melting zone and is of small amplitude, but it is present over a broad length of the GSC because mantle temperatures near the base of the melting zone are high over a broad length (Figures 13.6B, I). This effect can be seen in $\mathrm{Pb}$ flux curves averaged across the melting zone just north of the hotspot $(y=1,130)$ and well west of the hotspot $(y=1,400 \mathrm{~km})$ in Figures $13.6 \mathrm{O}$ and $\mathrm{H}$, respectively. In these plots, the relative areas under the curves for EC and DC do not appear to change substantially between the two locations. These predictions contrast with those of Model 1, in which the relative flux of $\mathrm{Pb}$ from $\mathrm{EC}$ versus DC far from the plume stem is shown to be less (Figure $13.3 \mathrm{H})$ than the relative flux just north of the plume stem (Figure 13.3O). The predicted compositions of Model 2 along the GSC are near the observed averages, but the lack of predicted variations in isotope $\left({ }^{206} \mathrm{~Pb} /{ }^{204} \mathrm{~Pb}\right)$ and incompatible trace-element $\left(\mathrm{La} / \mathrm{Sm}_{\mathrm{PM}}\right)$ ratios is inconsistent with the observed values along the GSC.

\subsubsection{Along-axis variations in incompatible element concentration}

The predicted variations in sodium content along the GSC are compared with observed concentrations that have been corrected for low-pressure fractionation $\left(\mathrm{Na}_{8.0}\right)$ using the same methodology as Cushman et al. [2004] (Figure 13.8). Because the models predict a primary

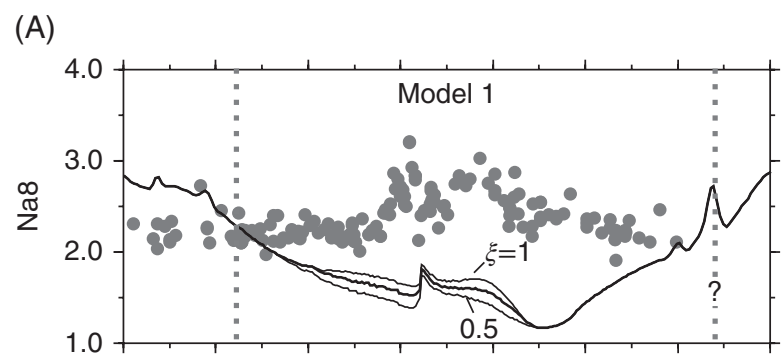

(B)

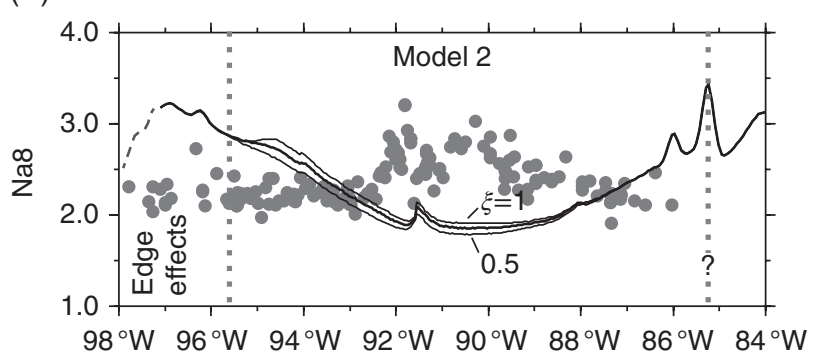

Figure 13.8 $\mathrm{Na}_{8.0}$ computed from data (dots) of Cushman et al. [2004] and Christie et al. [2005] compared to predictions for (A) Model 1 low-viscosity plume and (B) Model 2, with high viscosities due to water dependence for the model plume composition. Three curves are shown for $\xi=0.5,0.75$, and 1.0. Dotted vertical lines are as in Figures 13.4 and 13.7. magma composition, we account for the effects of olivine fractionation as $\mathrm{MgO}$ content decreases from an assumed initial value of $15 \%$ to $8.0 \%$ by adding 0.43 to the predicted $\mathrm{Na}_{2} \mathrm{O}$ contents (based on calculations of Langmuir et al. [1992]). Both models predict $\mathrm{Na}_{8.0}$ to be minimalnot maximal - nearest the hotspot center, and for $\mathrm{Na}_{8.0}$ to increase, rather than decrease, away from the hotspot center. In Model 2, the increases in $\mathrm{Na}_{8.0}$ reflect decreasing excess mantle temperatures and, thus, decreasing average extents of melting with distance away from the hotspot. In Model 1, this effect is enhanced because, again, the plume material feeding the melting zone of the GSC has already experienced some partial melting near the hotspot center. The models predicted similar trends for La and Sm individually, but Model 1 predicts a smaller increase in La than Sm with distance away from the hotspot center, and this produces a corresponding decrease in the $\mathrm{La} / \mathrm{Sm}_{\mathrm{PM}}$ ratio (Figure 13.4B). The predicted variations in the concentrations of incompatible elements for both models are clearly inconsistent with the observations (Figure 13.8).

\subsection{DISCUSSION}

\subsubsection{Model limitations and robustness of model results}

The general sense of the predicted geographic patterns in ${ }^{206} \mathrm{~Pb}^{204} \mathrm{~Pb}$ and $\mathrm{La} / \mathrm{Sm}$ compositions are robust outcomes of the processes simulated by the models. There are two main conditions on which the results depend: (1) The rate of mantle upwelling (and thus decompression) varies as a function of depth and geographic position, and (2) incompatible elements are extracted from the enriched geochemical component(s) at a greater depth than those from the depleted component(s).

Factors that would reduce (enhance) (1) spatial variations in the upwelling rate include higher (lower) average mantle viscosity and lower (higher) excess plume temperature. Factors that would reduce (enhance) (2) the difference in depth that incompatible elements are extracted include higher (lower) partition coefficients, or a smaller (larger) difference in the depth that EC and DC start melting. Thus, uncertainties in properties, such as those above, that influence the degree to which (1) and (2) occur are important to the magnitude of spatial geochemical variability but are not likely to change the sense of variability.

An important shortcoming of the models is the lack of direct simulations of melt migration and the associated chemical reactions. Condition (2) is therefore based on the assumption that melt-solid interaction is negligible, or that if it does occur, it preserves a proportionality between the flux of incompatible elements from EC and DC and the rate that these materials melt by decompression 
(i.e., Equations 13.3 and 13.4). It is reasonable to hypothesize that as melt produced from EC starts to migrate, this melt would tend to react with and strip incompatible elements from the solid, including DC. This reaction would be a source of incompatible element flux into the melt that differs from the decompression melting on which the current calculations are based. Recent fluid dynamic simulations have begun to examine the process of melt migration in a system of small blobs of more fusible material within a more refractory matrix [Weatherly and Katz 2012; Katz and Weatherly 2012]. These simulations predict melt that percolates out of a fusible blob is indeed highly reactive with the solid refractory matrix, but the result is a reaction infiltration instability which tends to focus the melt into localized melt channels. In contrast to pervasive, low-porosity melt percolation, which maximizes the volume of matrix rock that can interact with the melt, a large flux of melt delivered through high-porosity channels minimizes the volume of matrix that can interact with the melt. Hence, there is no reason to believe, based on the results of Weatherly and Katz [2012] and Katz and Weatherly [2012], that condition (2) is untrue. But certainly more work is needed to test the validity of (2) and the degree to which Equations 13.3 and 13.4 hold.

\subsubsection{The case for a low-viscosity Galápagos plume}

Between the two models examined, Model 1 produces predictions that are most consistent with the observations in terms of the patterns of magma production and isotope compositions, both around the archipelago and along the GSC. Mantle flow and melting beneath the Galápagos area is therefore more likely to be like that simulated in Model 1 than in Model 2. We note again that Model 1 simulates a low-viscosity plume without the effects of water on rheology.

The above result is puzzling because the dependence of mantle viscosity on water content is reasonably wellcharacterized [Hirth and Kohlstedt, 1996; Hirth and Kohlstaedt, 2003] and has been shown to be important in explaining analogous observations at the Iceland hotspot-ridge system [Ito et al., 1999; Bianco et al., 2013]. A possible explanation for this apparent contradiction comes from considering the strain-rate dependence of mantle rheology. Other simulations that incorporate these effects show that rapid strain rates associated with fast seafloor spreading [Ito et al., 2010] or plume-plate interaction [Ito et al., 2011] can lead to low viscosities for even dehydrated mantle. It is therefore possible that the slow-moving plates on the two sides of Iceland cause only a small strain-rate effect and thus allow dehydration to produce high viscosities in the melting zone below Iceland, as simulated by the prior studies [Ito et al., 1999; Bianco et al., 2013]. In contrast, the faster-moving plates in the Galápagos area cause larger strain-rate effects that dominate over the effects of dehydration, and thus lead to low viscosities much like those simulated in Model 1 . This possibility could be tested with further geodynamic modeling efforts. Another test of a low-viscosity Galápagos plume would be to measure the thickness of the ponding plume layer with a regional mantle seismic experiment.

\subsubsection{The nature of heterogeneity in the Galápagos plume and ambient mantle}

The incompatible element concentrations and $\mathrm{Pb}$ isotope compositions of EC and DC are the most poorly constrained parameters in the models and strongly influence the predicted spatial variability in magma composition. The ability for Model 1 to produce geochemical compositions that are comparable to those observed requires specific conditions on the mantle source. In particular, matching the variations in isotope compositions along the GSC requires that the refractory mantle material(s) represented by DC and the more fusible material(s) represented by EC have widely different isotopic characteristics. Isotopic end-members such DM and FOZO - on which DC and EC are based - are theoretical constructs often used in mixing calculations to explain variations in lava isotope compositions, but in general, material with these extreme end-member compositions may not necessarily exist in the mantle. Model 1, however, does require such material to exist within the Galápagos plume. Evidence for material with extreme compositions have been found at the Samoa hotspot [Jackson et al., 2007] but has yet to be discovered in the Galápagos area. The implication is that the Galápagos plume is composed of materials that have evolved very differently over geologic time to produce their strongly distinct isotope characteristics, but have since been mixed together so the heterogeneity is now present as small-scale blobs or veins [Sleep, 1984; Allégre and Turcotte, 1986].

If the nature of mantle heterogeneity is characteristically similar to that we have modeled, then our models show that it is possible for the observed horseshoe-shaped geochemical pattern (again combined with inward melt migration to restrict the pattern to the archipelago) and the gradients in isotope composition along the GSC to arise directly out of the dynamics of plume-ridge interaction with realistic plate motions and ridge geometry. These large-scale geochemical patterns do not necessarily require a regional zoning in the depleted versus the non-depleted materials across the hotspot-ridge system. Correspondingly, there is no requirement for mixing between the plume and ambient mantle along the ridge axis [Schilling et al., 1982; Schilling, 1985], entrainment of the ambient mantle, or toroidal circulation 
within the plume stem [Geist et al., 1988; Richards and Griffiths, 1989]. We cannot reject the possibility of such compositional zoning; however, it would be fortuitous for two unrelated factors - compositional zoning inherited from the lower mantle and variable mantle flow and melting in the upper mantle - to reinforce each other and both contribute to these large-scale patterns. Instead, we propose that the upper mantle processes simulated here control the overall horseshoe pattern and the geochemical gradients along the GSC ( 95.5 degrees $\mathrm{W}$ to approximately 85.3 degrees $\mathrm{W}$ ), whereas a slightly smaller scale of zoning of the composition within the non-depleted material of the Galápagos plume (i.e., the other isotopic components we have grouped with EC) creates the shorter-wavelength variations within the horseshoe [Geist et al., 1988; White et al., 1993] as was presented by Hoernle et al. [2000].

Another form of compositional zoning involves a Galápagos plume that is compositionally distinct from the ambient upper mantle - evident by the sudden, step-like change in composition near 95.5 degrees W [Ingle et al., 2010]. This step presumably marks the boundary between plume mantle to the east and a more depleted ambient mantle to the west. Indeed, a more depleted (ambient) mantle is modeled and shown to better match the compositions west of 95.5 degrees W (Figures 13.4B, C and 13.7B, C). While the ambient upper mantle in the region may be more depleted than the Galápagos plume, the observed magma compositions on the plume-influenced (east) side of 95.5 degrees $\mathrm{W}\left({ }^{206} \mathrm{~Pb} /{ }^{204} \mathrm{~Pb}\right.$ of $\left.18.7-18.8\right)$ which are reproduced by our model "plume" composition are not entirely uncommon at other normal (i.e., not hotspot-influenced) mid-ocean ridges [Ito and Mahoney, 2005b]. This supports the notion raised by Ito and Mahoney [2005b] that the composition of the lower mantle source feeding the Galápagos plume, and perhaps that of other plumes, is more similar to the composition of the upper mantle beneath mid-ocean ridges than previously thought.

\subsubsection{Incompatible element concentrations along the Galápagos Spreading Center}

A major shortcoming of both Model 1 and 2 is that they both predict trends of increasing, rather than decreasing, incompatible element concentrations along the GSC with distance from the hotspot center. A previous explanation for the observed variations in incompatible element concentration emphasizes the effects of a thermally buoyant and water-rich plume [Cushman et al., 2004]. Cushman et al. [2004] attributed the elevated incompatible-element concentrations near the hotspot center to an enhanced flux of low-degree melts from deep in the melting zone, created by rapid upwelling in the hydrous melting zone as well as an elevated water content near the hotspot, which expands the zone of deep melting.
In part, the Cushman et al. [2004] concept was tested here because Model 2 simulated the melting of mostly pristine mantle beneath the GSC and allowed for large vertical variations in mantle flow between a low-viscosity, deep, hydrous melting zone and a high-viscosity, dehydrated, shallow melting zone. Model 2 failed to predict the observed trends, perhaps due to a combination of it simulating insufficient along-axis variations in deep mantle upwelling, a uniform (rather than an along-axis varying) mantle water content, and a too-high excess plume temperature (the average excess was $130^{\circ} \mathrm{C}$, but a lower excess would also be within the seismic constraints of $30-150^{\circ} \mathrm{C}$ by Villagomez et al. [2007] and $130 \pm 60^{\circ} \mathrm{C}$ by Hooft et al. [2003]). Revisions to Model 2 might improve the results of the variations along the GSC, but it is unlikely that such a model would predict the horseshoeshaped geochemical pattern around the center of the hotspot. Model 1 thus remains favored.

Regarding Model 1, the discrepancy between the predicted and observed incompatible element concentrations along the GSC could possibly be reconciled by some form of zoning in incompatible element (and water [Cushman et al., 2004]) content within the plume stem. However, if the incompatible-element-enriched zones also have isotopic signatures of long-lived enrichment, then the zoning would have to be such that it would allow the enriched material(s) to appear with decreasing strength away from the hotspot to the east and west along the GSC, but appear with increasing strength on the west, north and south edges of the archipelago, as seen on the arms of the geochemical horseshoe. The distribution would have to be complex and not axisymmetric.

Another plausible solution that might not require zoning in mantle-incompatible content is that melt migration draws a relatively greater flux of incompatible-element-rich melt from the deep, pristine plume material to the ridge axis. Melt tends to migrate in the direction of decreasing pressure. The pressure gradient associated with the high-pressure region of the upwelling plume stem and the low-pressure region beneath the ridge axis [e.g. Spiegelman, 1993; Braun and Sohn, 2003] is in the right direction but may be too small in amplitude to significantly enhance the flux of incompatibleelement rich melts toward the ridge, especially for a low-viscosity plume [Ribe et al., 1995]. A stronger effect may be achieved with anisotropic melt percolation. Melt channels are known to form in response to mantle shear and are expected to be angled toward a ridge axis in the areas where the rate of horizontal mantle flow away from the ridge axis decreases with depth [Holtzman et al., 2003; Katz et al., 2006]. This sense of shear is expected to develop due to mantle flow driven passively by plate-spreading and would be further enhanced by northward flow of plume material toward the GSC. We 
hypothesize that this strong mantle shearing leads to a fabric of ridge-ward oriented melt channels that deliver the missing incompatible-element-rich melt to the GSC. Numerically testing this possibility is a computational challenge, especially in $3 \mathrm{D}$, but is likely to be possible in the near future.

\subsection{CONCLUSIONS}

Numerical models that simulate plume-ridge interaction with the realistic plate geometry, evolution, and motions for the past 6.3 Myr are used to explore the causes of the characteristic patterns in magma flux and composition of the Galápagos hotspot-ridge system. Model 1, which simulates a temperature-dependent and, thus, low-viscosity plume, is successful on many accounts; whereas Model 2, which simulates high viscosities in the shallowest upper mantle due to the extraction of water, is less successful. Model 1 predicts a zone of rapid melt production beneath an area that is localized to the Galápagos Archipelago and the various smaller volcanoes and volcanic lineaments between the archipelago and GSC. The model shows that a low-viscosity plume and the northward offset of the Western GSC away from the hotspot are essential for allowing a plume with a high excess temperature (average of $130^{\circ} \mathrm{C}$ and peak of $200^{\circ} \mathrm{C}$ ) to produce the relatively small crustal thickness anomalies $(2-3 \mathrm{~km})$ measured along the Western GSC.

Model 1 also shows that the upper mantle dynamics of plume-ridge interaction can create gradients in the isotopic expression of depleted versus enriched mantle materials along the GSC that are comparable to those observed between 95.5 and approximately 83.5 degrees W. Moreover, Model 1 predicts an arc of elevated ${ }^{206} \mathrm{~Pb} /{ }^{204} \mathrm{~Pb}$ along the perimeter of the hotspot melting zone, which, combined with inward melt migration toward the hotspot volcanoes (not modeled), could explain much of the observed horseshoe-shaped pattern around the perimeter of the archipelago. The main requirements are that the plume is everywhere a fine-scale mixture of materials that begin melting at different depths, and that these materials have isotope compositions that are more extreme than those measured in the erupted lavas, at least to date. With this type of mantle heterogeneity, the observed patterns in isotope compositions may not require the plume to be mixing with or entraining ambient mantle.

The failure of both models to predict the observed decreases in incompatible element concentration away from the hotspot center along the GSC indicates that the models are not including some important processes. One possibility is that there is some form of regional-scale zoning in the incompatible-element and water content in the plume. An alternative possibility is that melt migration is such that it delivers a larger flux of the deep, incompatible-element-rich melts from near the plume center toward the central part of the GSC. This possibility could be tested with calculations that simulate anisotropic melt migration. Tests for a low-viscosity Galápagos plume, as simulated in Model 1, could involve geodynamic models that incorporate a rheology that depends on strain rate as well as water content, a crustal seismic experiment to test for the large crustal thicknesses predicted along the Eastern GSC, as well as a regional mantle seismic experiment to constrain the thickness of the ponding plume material beneath the GSC.

\subsection{ACKNOWLEDGMENTS}

This study benefited from lively discussions with D. Toomey, J. Sinton and others at an AGU Chapman Conference, as well as comments on an earlier draft by J.J. Mahoney. We thank C. Farnetani and M. Kurz for their critical and constructive reviews. G. Ito was supported by grants NSF-0852115 and NSF-0855814, and Bianco by a NSF Postdoctoral Fellowship 0948345. SOEST contribution \#8785.

\section{REFERENCES}

Abouchami, W. et al. (2005), Lead isotopes reveal bilateral asymmetry and vertical continuity in the Hawaiian mantle plume, Nature, 434, 851-856.

Allégre, C.J., and D.L. Turcotte (1986), Implications of the two-component marble-cake mantle, Nature, 323, 123-127.

Allen, R.M. et al. (1999), The thin hot plume beneath Iceland, Geophys. J. Int., 137, 51-63.

Bianco, T.A., G. Ito, J. van Hunen, M.D. Ballmer, and J.J. Mahoney (2008), Geochemical variation at the Hawaiian hot spot caused by upper mantle dynamics and melting of a heterogeneous plume, Geochem. Geophys. Geosys., 9(11), Q11003, doi:11010.11029/12008GC002111.

Bianco, T.A., G. Ito, J. van Hunen, M. D. Ballmer, and J.J. Mahoney (2011), Geochemical variations at intraplate hot spots caused by viable melting of a veined mantle plume, Geochem. Geophys. Geosys., 12(7, Q0AC13), doi:10.1029/20111GC003658.

Bianco, T.A., G. Ito, J. van Hunen, J.J. Mahoney, and M.D. Ballmer (2013), Geochemical variations at ridge-centered hotspots caused by variable melting of a veined mantle plume, Earth Planet. Sci. Lett., 371-372, 171-201.

Braun, M.G., and R.A. Sohn (2003), Melt migration in plumeridge systems, Earth Planet. Sci. Lett., 213, 417-430.

Canales, J.P., G. Ito, R. Detrick, and J. Sinton (2002), Crustal thickness along the western Galápagos Spreading Center and the compensation of the Galápagos hotspot swell, Earth Planet. Sci. Lett., 203, 311-327.

Christensen, U. (1984), Convection with pressure- and temperature-dependent non-Newtonian rheology, Geophys. J. R. Astr. Soc, 77, 343-384. 
Christie, D.M., R. Werner, F. Hauf, K. Hoernle, and B. Hanan (2005), Morphological and geochemical variations along the eastern Galápagos Spreading Center, Geochem. Geophys. Geosyst., 6, Q01006, doi:01010.01029/02004GC000714.

Cushman, B.J., J.M. Sinton, G. Ito, and J.E. Dixon (2004), Glass composition, plume-ridge interaction, and hydrous melting along the the Galápagos Spreading Center, $90.5^{\circ} \mathrm{W}$ to $98^{\circ} \mathrm{W}$, Geochem. Geophys. Geosys., 5(Q08E17), doi:10.1029/2004GC000709.

Detrick, R.S. et al. (2002), Correlated geophysical, geochemical and volcanological manifestations of plume-ridge interaction along the Galápagos Spreading Center, Geochem., Geophys., Geosys., 3 (10), 8501, doi:8510.1029/ 2002GC000350.

Farnetani, C.G., and A.W. Hofman (2010), Dynamics and internal structure of the Hawaiian plume, Earth. Planet. Sci. Lett., 295, 231-240.

Feighner, M.A., L.H. Kellogg, and B.J. Travis (1995), Numerical modeling of chemically buoyant mantle plumes at spreading ridges, Geophys. Res. Lett., 22, 715-718.

Geist, D. (1992), An appraisal of melting processes and the Galápagos Hotspot: Major- and trace-element evidence, J. Volc. Geotherm. Res., 52, 65-82.

Geist, D.J., W.M. White, and A.R. McBirney (1988), Plumeasthenosphere mixing beneath the Galápagos archipelago, Nature, 333, 657-660.

Gibson, S.A., and D. Geist (2010), Geochemical and geophysical estimates of lithospheric thickness variation beneath Galápagos, Earth. Planet. Sci. Lett., 300, 275-286.

Gripp, A.E., and R.G. Gordon (1990), Current plate velocities relative to the hotspots incorporating the NUVEL-1 global plate motion model, Geophys. Res. Lett., 17, 1109-1112.

Harpp, K., and D. Geist (2002), Wolf-Darwin lineament and plume-ridge interaction in northern Galápagos, Geoch. Geophys. Geosys., 3(11), doi:10.1029/2002GC000370.

Harpp, K.S., and W.M. White (2001), Tracing a mantle plume: Isotopic and trace-element variations of Galápagos seamounts, Geochem. Geophys. Geosys., 2(6), doi:10.1029/2000GC000137.

Hirth, G., and D.L. Kohlstedt (1996), Water in the oceanic upper mantle: Implications for rheology, melt extraction, and the evolution of the lithosphere, Earth Planet. Sci. Lett., 144, 93-108.

Hirth, G., and D.L. Kohlstaedt (2003), Rheology of the upper mantle and the mantle wedge: A view from the experimentalists, in Inside the Subduction Factory, Geophys. Monogr. Ser., edited by J. Eiler, pp. 83-105, AGU, Washington D.C.

Hoernle, K.R. et al. (2000), Existence of complex spatial zonation in the Galápagos plume for at least 14 m.y., Geology, 28, 435-438.

Holtzman, B.K. et al. (2003), Melt segregation and strain partitioning: Implications for seismic anisotropy and mantle flow, Science, 301, 1227-1230.

Hooft, E.E., D.R. Toomey, and S.C. Solomon (2003), Anomalously thin transition zone beneath the Galápagos hotspot, Earth Planet. Sci. Lett., 216, 55-65.

Ingle, S. et al. (2010), Mechanisms of geochemical and geophysical variations along the western Galápagos Spreading Center, Geochem. Geophys. Geosys., 11(4), Q04003, doi:04010.01029/ 02009 GC002694.
Ito, G., and J. Lin (1995), Mantle temperature anomalies along the present and paleoaxes of the Galápagos Spreading Center as inferred from gravity analyses, J. Geophys. Res., 100, 3733-3745.

Ito, G., and J. Mahoney (2005a), Flow and melting of a heterogeneous mantle: 1 . Importance to the geochemistry of ocean island and mid-ocean ridge basalts, Earth Planet. Sci. Lett., 230, 29-46.

Ito, G., and J. Mahoney (2005b), Flow and melting of a heterogeneous mantle: 2. Implications for a non-layered mantle, Earth Planet. Sci. Lett., 230, 47-63.

Ito, G., J. Lin, and C. Gable (1997), Interaction of mantle plumes and migrating midocean ridges: Implications for the Galápagos plume-ridge system, J. Geophys. Res., 102, 15, 403-15, 417.

Ito, G., Y. Shen, G. Hirth, and C. Wolfe (1999), Mantle flow, melting, and dehydration of the Iceland mantle plume, Earth Planet. Sci. Lett., 165, 81-96.

Ito, G., R. Dunn, and D.W. Forsyth (2010), A study of shortperiod surface wave data, geodynamic models, and the rheology and dynamics of the mantle beneath the East-Pacific Rise, Abstract DI34A-01, 2010 Fall Meeting, AGU, San Francisco, Calif., 13-17 Dec.

Ito, G. et al. (2011), Mantle flow and seismic anisotropy associated with plume-plate interaction, Abstract DI51C-07 presented at 2011 Fall Meeting, AGU, San Francisco, Calif., 5-9 Dec.

Jackson, M.G. et al. (2007), The return of subducted continental crust in Samoan lavas, Nature, 448, doi:10.1038/ nature 06048 .

Johnson, K.T.M., H.J.B. Dick, and N. Shimizu (1990), Melting in the oceanic upper mantle: An ion microprobe study of diopsides in abyssal peridotites, J. Geophys. Res., 95, 2661-2678.

Katz, R.F., M. Spiegelman, and C.H. Langmuir (2003), A new parameterization of hydrous mantle melting, Geochem. Geophys. Geosys, 4(9), 173, doi:110.1029/2002GC000433.

Katz, R.F., M. Spiegelman, and B.K. Holtzman (2006), The dynamics of melt and shear localization in partially molten aggregates, Nature, 442, 676-679, doi:610.1038/ nature 05039 .

Katz, R. F. and S. M. Weatherley (2012), Consequences of mantle heterogeneity for melt extraction at mid-ocean ridges, Earth Planet. Sci. Lett., 335-336, 226-237.

Kogiso, T., M.M. Hirschmann, and P.W. Reiners (2004), Length scales of mantle heterogeneities and their relationship to ocean island basalt geochemistry, Geochim. Cosmochim. Ac., 68(2), 345-360.

Langmuir, C.H., E.M. Klein, and T. Plank (1992), Petrological systematics of mid-ocean ridge basalts: Constraints on melt generation beneath ocean ridges, in Mantle flow and melt generation at mid-ocean ridges, edited by J. Phipps Morgan, D.K. Blackman and J.M. Sinton, pp. 183-280, Amer. Geophys. Union.

McDonough, W.F., and S.-S. Sun (1995), The composition of the Earth, Chem. Geol., 120, 223-253.

Mittelstaedt, E. et al. (2012), Multiple expressions of plumeridge interaction in the Galápagos: Volcanic lineaments and ridge jumps, Geochem. Geophys. Geosys., 13 (13), Q05018, doi: 05010.01029/02012GC004093. 
Mittelstaedt, E., S. Soule, K.S. Harpp, and D. Fornari (2014), Variations in crustal thickness, plate rigidity, and volcanic processes throughout the Northern Galápagos Volcanic Province, Chapter 14, this volume.

Morgan, W.J. (1978), Rodriguez, Darwin, Amsterdam,..., A second type of hotspot island, J. Geophys. Res., 83, 5355-5360.

Putirka, K. (2012), Excess temperatures at ocean islands: Implications for mantle layering and convection, Geology, $36(4), 283-286$.

Ribe, N. (1996), The dynamics of plume-ridge interaction 2. Off-ridge plumes, J. Geophys. Res., 101, 16, 195-116,204.

Ribe, N., U.R. Christensen, and J. Theissing (1995), The dynamics of plume-ridge interaction, 1: Ridge-centered plumes, Earth Planet. Sci. Lett., 134, 155-168.

Richards, M.A., and R.W. Griffiths (1989), Thermal entrainment by deflected mantle plumes, Nature, 342, 900-902.

Salters, V.J.M., and A. Stracke (2004), Composition of the depleted mantle, Geochem. Geophys. Geosyst., 5(5), Q05004, doi:05010.01029/02003GC000597.

Schilling, J.-G. (1985), Upper mantle heterogeneities and dynamics, Nature, 314, 62-67.

Schilling, J.-G. (1991), Fluxes and excess temperatures of mantle plumes inferred from their interaction with migrating mid-ocean ridges, Nature, 352, 397-403.

Schilling, J.-G., R.H. Kingsley, and J.D. Devine (1982), Galápagos hot spot-spreading center system 1. Spatial petrological and geochemical variations $\left(83^{\circ} \mathrm{W}-101^{\circ} \mathrm{W}\right)$, J. Geophys. Res., 87, 5593-5610.

Schilling, J.G., D. Fontignie, J. Blichert-Toft, R. Kingsley, and U. Tomza (2003), Pb-Hf-Nd-Sr isotope variations along the Galápagos Spreading Center $\left(101-83^{\circ} \mathrm{W}\right)$ : Constraints on the dispersal of the Galápagos mantle plume, Geochem. Geophys. Geosys., 4 (10) (8512), doi:10.1029/2002GC000495.

Sinton, J., R. Detrick, J.P. Canales, G. Ito, and M. Behn (2003), Morphology and segmentation of the Western Galápagos spreading center, $90.5-98^{\circ} \mathrm{W}$ : Plume-ridge interactions at an intermediate spreading ridge, Geochem. Geophys. Geosys., 4 (12), 8515, doi:8510.1029/2003GC000609.

Sleep, N.H. (1984), Tapping of magmas from ubiquitous mantle heterogeneities: An alternative to mantle plumes?, J. Geophys. Res., 89, 10, 029-10, 041.

Sleep, N.H. (1990), Hotspots and mantle plumes: Some phenomenology, J. Geophys. Res., 95, 6715-6736.

Sparks, D.W., and E.M. Parmentier (1991), Melt extraction from the mantle beneath spreading centers, Earth Planet. Sci. Lett., 105, 368-377.
Spiegelman, M. (1993), Physics of melt extraction: Theory, implications and applications, Phil. Trans. R. Soc. Lond., Ser. A, 342, 23-41.

Stracke, A., A.W. Hofmann, and S.R. Hart (2005), FOZO, HIMU, and the rest of the mantle zoo, Geochem. Geophys. Geosyst., 6, Q05007, doi:05010.01029/02004GC000824.

Verma, S.P., and J.-G. Schilling (1982), Galápagos hot spotspreading center system $2 .{ }^{87} \mathrm{Sr} /{ }^{86} \mathrm{Sr}$ and large ion lithophile element variations $\left(85^{\circ} \mathrm{W}-101^{\circ} \mathrm{W}\right)$, J. Geophys. Res., 87, $10,838-10,856$.

Villagomez, D.R., D.R. Toomey, E.E. Hooft, and S.C. Solomon (2007), Upper mantle structure beneath the Galápagos Archipelago from surface wave tomography, J. Geophys. Res., 112(B07303), doi:10.1029/2006JB004672.

Weis, D., M.O. Garcia, J.M. Rhodes, M. Jellinek, and J.S. Scoates (2011), Role of the deep mantle in generating the compositional asymmetry of the Hawaiian mantle plume, Nature, 4, DOI: 10.1038/NGEO1328.

Weatherly, S. M., and R. F. Katz (2012), Melting and channelized magmatic flow in chemically heterogeneous, upwelling mantle, Geochem. Geophys. Geosys., 13 (1), Q0AC18, doi:10.1029/2011GC003989.

White, W.M., A.R. McBirney, and R.A. Duncan (1993), Petrology and geochemistry of the Galápagos Islands: Portrait of a pathological mantle plume, J. Geophys. Res., 98, 19, 533-519, 563.

Wilson, D.S., and R.N. Hey (1995), History of rift propagation and magnetization intensity for the Cocos-Nazca spreading center, J. Geophys. Res., 100, 10, 041-10,056.

Wolfe, C., I.T. Bjarnason, J.C. Van Decar, and S.C. Solomon (1997), Seismic structure of the Iceland mantle plume, Nature, 385, 245-247.

Wolfe, C.J. et al. (2009), Mantle shear-wave velocity structure beneath the Hawaiian hot spot, Science, 326, 1388-1390.

Workman, R.K., and S. Hart (2005), Major and trace element composition of the depleted MORB mantle (DMM), Earth Planet. Sci. Lett., 231, 53-72.

Workman, R., E.H. Hauri, S.R. Hart, J. Wang, and J. Blusztajn (2006), Volatile and trace elements in basaltic glasses from Samoa: Implications for water distribution in the mantle, Earth. Planet. Sci. Lett., 241, 932-951.

Zhong, S., M.T. Zuber, L.N. Moresi, and M. Gurnis (2000), The role of temperature-dependent viscosity and surface plates in spherical shell models of mantle convection, J. Geophys. Res., 105, 11, 063-11,082. 
